DOI: https://doi.org/10.30525/978-9934-26-108-4-4

Evgeniya Medvedkina

Doctor of Economics Sciences, Professor, Head of the Department of World Economy

Rostov State University of Economics

Tamara Ishchenko

Postgraduate Student at the Department of World Economy

Rostov State University of Economics

\title{
ENSURING THE ECONOMIC SECURITY \\ OF THE STATE IN THE CONDITIONS OF THE PANDEMIC: THEORETICAL AND APPLIED THINKING
}

\begin{abstract}
Summary
The problem of ensuring the economic security of the state is quite urgent. This study examines theoretical approaches to defining this definition, as well as the structural elements of the concept of economic security. The aim of the study is to identify the theoretical and methodological substantiation of the economic security of the state and the development of strategic directions for ensuring the economic security of the Russian Federation in the face of modern global challenges. The stages for assessing the level of economic security of the state are determined. Based on the existing methods for assessing the economic security of the state, a methodological approach to this assessment is proposed, taking into account the totality of macroindicators, industry, financial and social indicators. The calculation of the indicators of the economic security of the Russian Federation showed that the indicators do not go beyond the threshold values. The results of constructing an econometric model made it possible to determine the indicators of national economic security that have the most significant impact on the level of economic development of the state, as well as to identify internal and external threats to the Russian Federation. Thus, we can conclude that the economic security of the state can be represented as the state of protection of the national economy from external and internal threats, which ensures the progressive development of society, its economic and socio-political stability, despite the presence of unfavorable external and internal factors; ensuring national economic security and neutralizing all possible threats is the fundamental task of the state government. The level of economic development of the country as a whole and the quality of life of its citizens depend on the success and effectiveness of countermeasures.
\end{abstract}




\section{Введение}

Обеспечение экономической безопасности остается одной из основных задач государства, выстраивающего устойчивые международные экономические отношения. В условиях распространения пандемии COVID-19 социально-экономическая обстановка в мире ухудшилась, что, в свою очередь, не могло не отразиться на уровне экономической безопасности всех стран мира.

Исследования по данной проблематике актуальны, так как в последние годы вопросы обеспечения национальной экономической безопасности усложняются новыми аспектами ее теоретического содержания. Это происходит в связи с изменениями мировой экономики на институциональном уровне вследствие её модернизации. В процессе вышеуказанной трансформации образовываются различные направления и аспекты мирового хозяйства и национальных экономик разных стран.

На современном этапе развития сложившаяся на международной арене ситуация требует различных способов решения имеющихся задач по обеспечению экономической безопасности с научной точки зрения. Эти способы должны учитывать возможные угрозы экономической безопасности, в частности влияние постпандемических последствий, и предотвращать их, обеспечивая устойчивое развитие регионов. Во многих современных научных работах авторы изучают и предлагают различные новые концепции формирования обеспечения экономической безопасности путем использования особых методов и механизмов защиты экономических интересов. В российской науке проблему экономической безопасности рассматривали такие ученые, как Л.И. Абалкин [1], С.Ю. Глазьев, А.А. Илларионов [3], Е.Е. Румянцева, В.К. Сенчагов [6] и др. Целью исследования является выявление теоретико-методологического обоснования экономической безопасности государства и разработка стратегических направлений обеспечения экономической безопасности страны в условиях современных глобальных вызовов и пандемии.

\section{Раздел 1. Теоретические подходы к определению экономической безопасности}

Практически во всех исследованиях последних лет по изучаемой теме основополагающим элементом современных стратегий обеспечения национальной безопасности является экономический аспект.

Опираясь на научный опыт предыдущих лет, можно утверждать, что в различные исторические периоды отдельные государства по-разному подходили к формированию национальной экономической безопасности. Такие отличия определяются, главным образом, развитием и изменением характера возможных угроз с течением времени. В настоящее время можно говорить о новом сформировавшемся факторе, влияющем на угрозы, а именно о 
национальной уязвимости и экономической устойчивости. В связи с этим довольно длительное время ученые занимаются формированием определения экономической безопасности и её объектами.

Необходимо сказать о том, что вопросами экономической безопасности занимались представители многих экономических школ. В связи с этим в отдельных школах сложились определенные подходы к пониманию категории национальной экономической безопасности. Так, например, в классической школе экономическая безопасность достигается экономикой государства без вмешательства государства через абсолютные и сравнительные преимущества. Согласно неоклассической школе, напротив, для обеспечения экономической безопасности требуется государственное регулирование экономики, которое будет контролировать стабильное и справедливо распределение материальных благ. Представители кейнсианской школы считали, что экономическая безопасность страны понимается как защита от внутренних макроэкономических угроз. Согласно основным положениям меркантилизма, экономическая безопасность понимается как протекционизм во внешней торговле и достигается путем ограничения импорта товаров через установление высоких цен на импортируемые товары и запрещение вывоза золота и серебра из страны. В позднем меркантилизме трансформируется в достижение положительного торгового баланса за счет превышения экспорта над импортом [5].

В ходе научных исследований второй половины XX и начала XXI века были созданы несколько основных подходов к определению национальной экономической безопасности $[7 ; 8 ; 10]$ :

- азиатский подход основан на цивитацентричной парадигме. При азиатском подходе понятие экономической безопасности предлагается понимать в основном через общепринятые терминах, т. е. «экономическая безопасность той или иной системы означает статус подсистемы, которая обеспечивает способность достигать цели всей системы» [5]. Однако данное определение рассматривает экономическую безопасность как совокупность производственных мощностей государства. Благодаря этому оно становится более устойчивым к различным угрозам, возникающим путем накопления слабых мест. Таким образом, в этом подходе суть экономической безопасности можно обозначить как особую деятельность, путём которой органы государственного управления обеспечивают защиту национальных интересов, развитие социально ориентированного государства и достаточный военный потенциал;

- англо-саксонский подход предполагает разделение экономической безопасности граждан и государства с неявным превалированием хомоцентричной парадигмы. Он подразумевает, что вследствие произошедших трансформаций в мировом хозяйстве и изменений на международной арене появились новые аспекты и вопросы, на которые 
необходимо ответить для обеспечения экономической безопасности государства и мирового сообщества в целом.

Существует также российский подход к понятию категории экономической безопасности. В рамках этого подхода экономическая безопасность рассматривается как совокупность и внешних, и внутренних факторов, обеспечивающих независимость национальной экономики, ее стабильность и устойчивость, способность к постоянному обновлению и самосовершенствованию. Механизм обеспечения экономической безопасности страны предполагает ориентацию на определенные сферы управления, в которых государство сможет постепенно укреплять свои позиции на международной арене и в то же время создавать инновации, не теряя темпов экономического роста.

Из рассмотренных подходов к понятию экономической безопасности следует, что национальная безопасность состоит из удовлетворения основных потребностей общества, которые необходимы для его стабильного развития: физиологических, социально-экономических, духовных и ситуационных ресурсов, технологий, информации и моральных идеалов. Концепция экономической безопасности достаточно структурирована, и все элементы этой системы тесно связаны друг с другом (рис. 1).

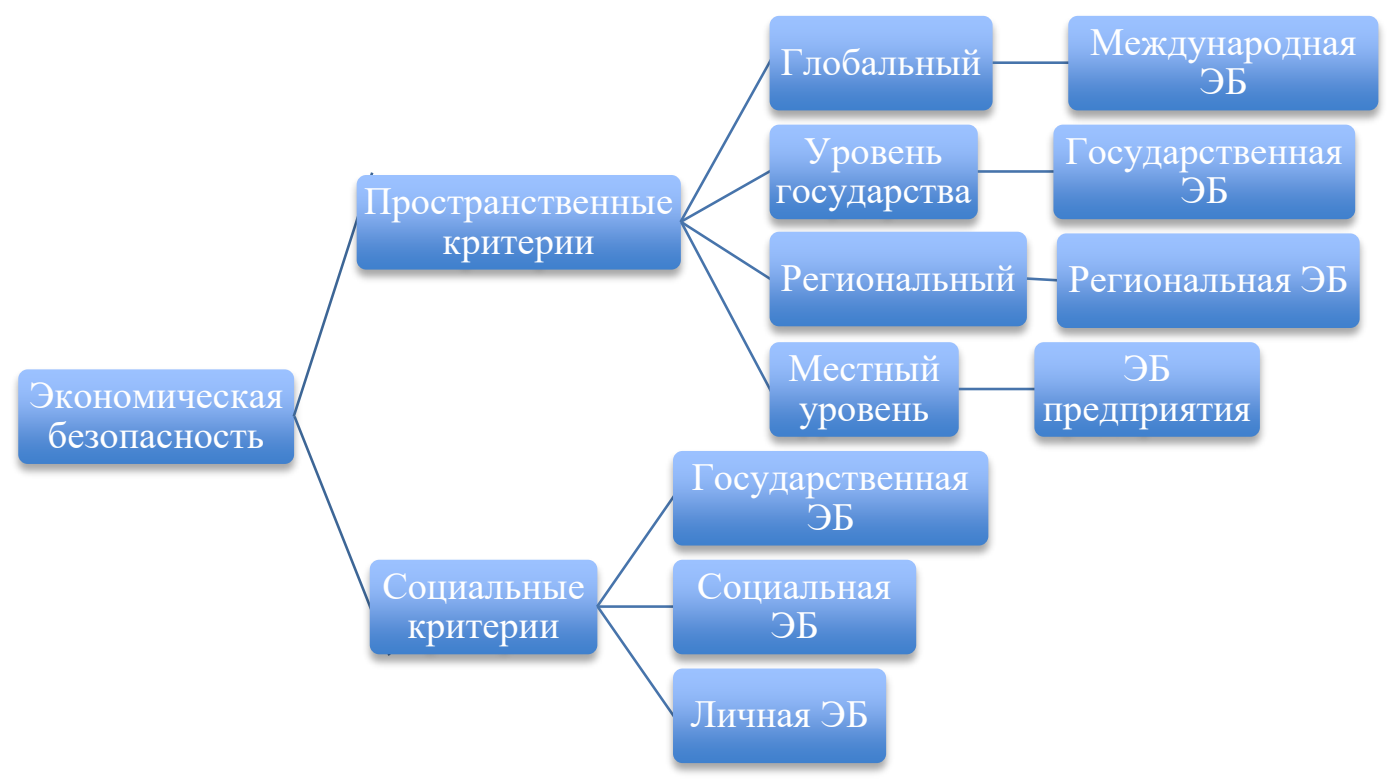

\section{Рис. 1. Структура экономической безопасности}

Кроме того, взаимодействие элементов экономической безопасности приводит к формированию сложной многоуровневой системы, включающей такие структурные элементы, как экономическая независимость, устойчивость национальной экономики, способность к саморазвитию и прогрессу. 
Исходя из общепризнанных определений, можно сделать вывод, что обеспечение безопасности является сложным и многогранным процессом трансформаций в социальной и экономической сферах, которые являются частью национальной экономической безопасности страны и на которые влияют частые изменения в среде национального воспроизводства, а также современные экзогенные и эндогенные факторы, включающие в себя угрозы для государственной экономики. Этот процесс является основной обязанностью государства и осуществляется путем совместной работы с экономическими агентами. Именно по уровню национальной безопасности можно судить о том, могут ли соответствующие государственные органы и институты обеспечивать защиту своих национальных экономических и социальных интересов. Из этого следует вывод, что экономический элемент национальной безопасности необходимо изучать совместно с социальными и другими интересами государства.

Основываясь на различных научных трудах, можно сделать вывод, что в контексте отдельной страны не может существовать понятие абсолютной экономической безопасности, т. к. с усилением процесса глобализации появляются новые внешние и внутренние угрозы.

На основании исследований различных экономических школ в области экономической безопасности под экономической безопасностью государства предлагается понимать способность экономики противостоять внутренним угрозам и внешним глобальным вызовам экономического, социального, политического или другого происхождения, а также нейтрализовать и/или минимизировать ущерб от потенциальных и реальных угроз.

\section{Раздел 2. Методология оценки уровня экономической безопасности государства}

Обеспечение национальной экономической безопасности - одна из важнейших задач правительства государства. Анализ экономической безопасности страны должен учитывать множество аспектов, так как современные угрозы экономической безопасности государства являются как внутренними, так и внешними. Многочисленные факторы: последствия пандемии COVID-19, снижение уровня жизни населения, значительные инфляционные процессы, экономический и социальный разрывы между бедными и богатыми негативно сказываются на стабильности экономической безопасности государства в целом.

Следует отметить, что для государства не может существовать понятие абсолютной экономической безопасности, на неё не могут влиять все новые эндогенные и экзогенные факторы, среди которых можно выделить географическое положение, запасы государственных природных ресурсов, национальный промышленный и сельскохозяйственный потенциал, социально-демографическую 
ситуацию в стране и уровень эффективности государственного аппарата. Для оценки уровня экономической безопасности государства необходимо определить следующие этапы (рис. 2) [2].

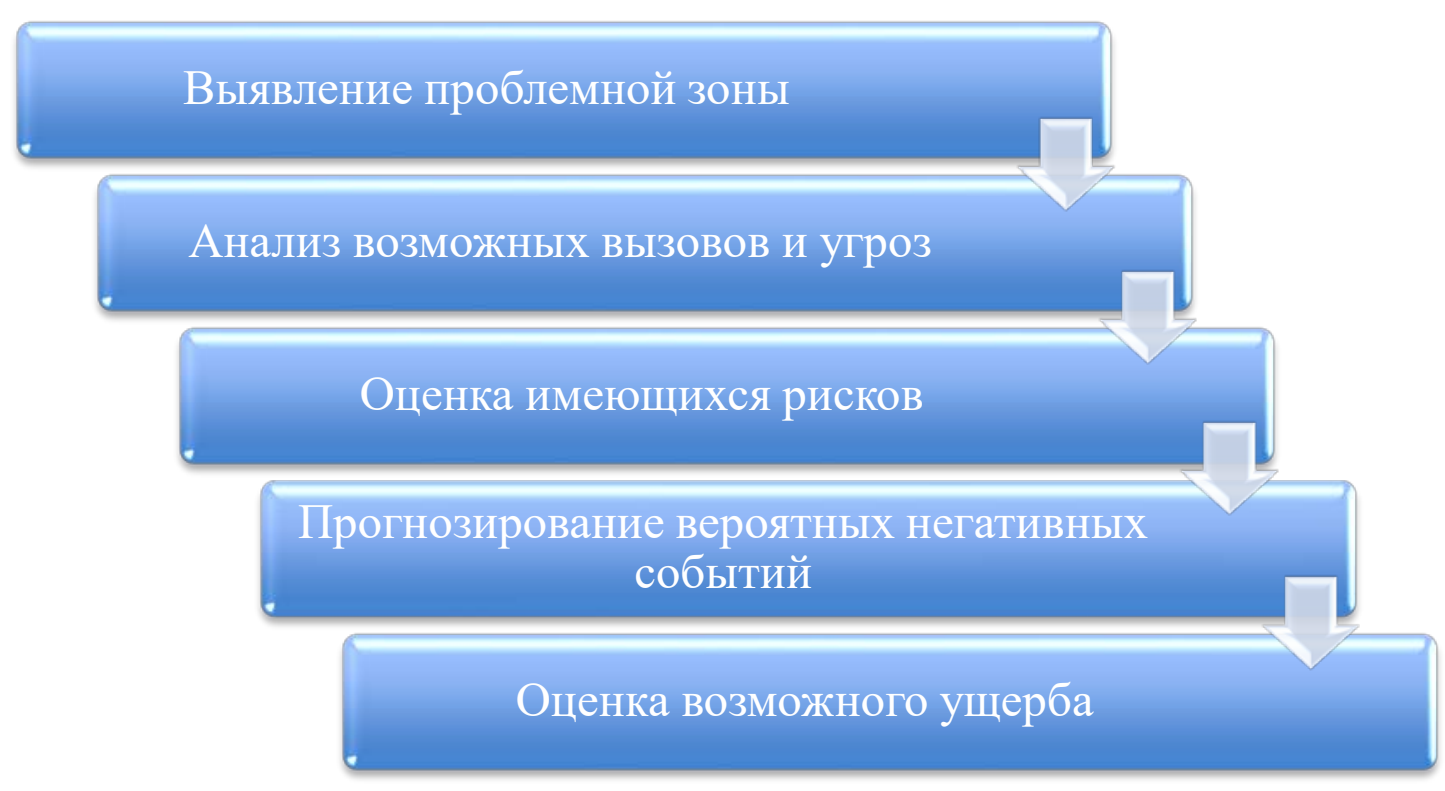

\section{Рис. 2. Структура оценки уровня экономической безопасности государства}

При оценке уровня экономической безопасности необходимо учитывать допустимые пределы пороговых показателей экономической безопасности, т. к. интегрированный показатель общей безопасности формируется из различных постоянно изменяющихся индикаторов. Согласно методике оценки экономической безопасности государства В.К. Сенчагова [6], необходимо учитывать следующие показатели: «уровень безработицы (доля экономически активного населения); децильный коэффициент дифференциации доходов населения (соотношение $10 \%$ доходов более и $10 \%$ менее обеспеченного населения); темпы роста потребительских цен; уровень государственного внешнего и внутреннего долга в процентах от ВВП; уровень устойчивости здравоохранения, культуры, науки и образования в процентах от ВВП; уровень ежегодного обновления оружия, военной и специальной техники; уровень военно-технического персонала» [6].

Однако такая методология имеет узкую экономическую направленность, почти не оценивая социальные и другие показатели развития экономики государства.

Одна из методик оценки НЭБ предлагает анализировать уровень экономической безопасности страны путем исследования таких групп показателей: финансовые показатели - ВВП, ВВП на душу населения и валовое накопление основного капитала; технико-технологические 
показатели - количество организаций-экспортеров (\% от общего количество зарегистрированных предприятий); инновационные и инвестиционные показателей - инвестиции в основной капитал, инвестиции в основной капитал на душу населения, внутренние расходы на исследования и разработки, научно-исследовательские и опытноконструкторские организации; показатели инфраструктуры - уровень использования информационных технологий в организациях, использование электронного документооборота в организациях, уровень использования инновационных технологий при производстве продукции для национального и международного рынков; показатели экологии выбросы загрязняющих веществ в атмосферный воздух от стационарных источников, использование пресной воды, объем оборотной и последовательно используемой воды, доля захваченных и нейтрализованных загрязняющих веществ в общем количестве отходов загрязняющих веществ из стационарных источников; политико-правовые показатели - количество зарегистрированных преступлений на 100 тыс. человек; показатели труда - численность населения, реальные доходы населения, среднемесячная номинальная начисленная заработная плата работников организаций, средние темпы роста; интеллектуальные показатели - количество профессиональных образовательных организаций, готовящих квалифицированных работников, количество квалифицированной рабочей силы, выпуск бакалавров, специалистов, магистров, численность персонала, занятого исследованиями и разработками. Основным недостатком этой методологии является тот факт, что она практически никак не охватывает макроэкономические показатели развития государства. Как уже говорилось выше, при объективной оценке НЭБ необходимо одинаковое внимание уделять анализу как внутренних, так и внешних факторов развития. В качестве наиболее объективного метода оценки экономической безопасности государства нами была выбрана система, которая предполагает разделение факторов экономической безопасности на четыре сферы: макроиндикаторы, отраслевые, финансовые и социальные индикаторы (табл. 1) [9].

Перечисленные показатели наиболее полно могут отобразить способность экономики государства противостоять внутренним угрозам и внешним глобальным вызовам экономического, социального, политического или другого происхождения, а также возможность нейтрализовать ущерб от потенциальных и реальных угроз.

Таким образом, можно сделать вывод, что для определения национальных экономических интересов необходимо провести исследование текущего состояния развития государства. В разных методиках это достигается анализом различных показателей и индикаторов. В некоторых подходах анализируют исключительно показатели экономического роста, в других - применяют комплексный анализ показателей всех сфер жизни. 
Основные индикаторы для оценки экономической безопасности государства

\begin{tabular}{|c|c|}
\hline Пфтруппа индмкаторов & Индмкатор \\
\hline \multirow{3}{*}{ Макроиндикаторы } & $\begin{array}{l}\text { Уровень безработищы, \% к экономически активному } \\
\text { населению }\end{array}$ \\
\hline & Уровень инфляции, \% \\
\hline & $\begin{array}{l}\text { Дефицит федерального (центрапьного) бюджета, \% к } \\
\text { ВВ }\end{array}$ \\
\hline \multirow{4}{*}{ Отраслевые индикаторы } & Валовый сбор зерновых, млн тон \\
\hline & Доля расходов на оборону, \% к ВВП \\
\hline & $\begin{array}{l}\text { Доля инновационной продукции в общем объёме } \\
\text { промышленной продукции, \% }\end{array}$ \\
\hline & $\begin{array}{l}\text { Доля мапиностроения и металлообработки в } \\
\text { промышленном производстве, \% }\end{array}$ \\
\hline \multirow{5}{*}{ Финансовые индикаторы } & Валовое накоштение основного капитала, \% к ВВП \\
\hline & Объем государственных резервов, \% к ВВП \\
\hline & Уровень монетизации, \% к ВВП \\
\hline & Внештний долг, \% к ВВП \\
\hline & $\begin{array}{l}\text { Доля расходов бюджета на обслуживание } \\
\text { государственного долга, \% от общего объёма } \\
\text { расходов бюджета }\end{array}$ \\
\hline \multirow{4}{*}{ Соңиальные индикаторы } & Доля затрат на науку и образование, \% к ВВП \\
\hline & $\begin{array}{l}\text { Доля лиц с денежным доходом ниже прожиточного } \\
\text { уровня во всей численности населения, \% }\end{array}$ \\
\hline & $\begin{array}{l}\text { Децильный коэффициент дифференциации доходов } \\
\text { населения }\end{array}$ \\
\hline & $\begin{array}{l}\text { Доля продовопьствия, постушившего по импорту, в } \\
\text { общем объеме продовольственных ресурсов, \% }\end{array}$ \\
\hline
\end{tabular}

\section{Раздел 3. Оценка индикаторов}

\section{экономической безопасности Российской Федерации}

В Российской Федерации принято рассматривать национальную экономическую безопасность в основном по тем индикаторам, которые смогут отразить её экономический рост. Так, согласно сайту Федеральной службы государственной статистики [4], в Российской Федерации пользуются следующими показателями для определения состояния национальной экономической безопасности: валовой внутренний продукт; государственные расходы на национальное вооружение; государственные резервы (включая запасы золота) в стоимостном выражении; валовое накопление основного капитала; приток прямых иностранных инвестиций; уровень инфляции; объем экспорта товаров и услуг; уровень вовлеченности населения в рабочую силу.

Данные показатели показывают, на каком уровне развития находится экономическая система государства, а также помогают определить вектор этого развития. Отрицательная динамика этих индикаторов будет свидетельствовать о возможных негативных последствиях для экономики в будущем и создавать опасность потери контроля над 
социально-экономической сферой страны, иными словами, будет подрываться ее экономическая безопасность и возникать угроза дальнейшего гармоничного развития страны.

При этом состояние экономической безопасности государства необходимо оценивать комплексно, ориентируясь на показатели, которые могут показать не только уровень развития его экономики, но и социальной сферы. Поэтому для того, чтобы точнее определить уровень национальной экономической безопасности, в ходе исследования было проанализировано состояние экономической безопасности России также через индикаторы, которые смогут показать уровень ЭБ государства с точки зрения четырех групп индикаторов: макроиндикаторов, отраслевых, финансовых и индикаторов социального развития. В табл. 2 представлены их фактические значения 2018 г. с пороговыми.

Таблица 2

\section{Пороговые значения индикаторов оценки экономической безопасности Российской Федерации}

\begin{tabular}{|c|c|c|c|}
\hline $\begin{array}{l}\text { Подруппа } \\
\text { мндккаторов }\end{array}$ & Индакатор & $\begin{array}{l}\text { Поротовое } \\
\text { значение }\end{array}$ & $\begin{array}{l}\text { Значение в } \\
2018 \text { г. }\end{array}$ \\
\hline \multirow{3}{*}{ Макроиндикаторы } & $\begin{array}{l}\text { Уровень безработицы, \% к } \\
\text { экономически активному населению }\end{array}$ & $\leq 8$ & 4,74 \\
\hline & У ровень инфляции, \% & $\leq 25$ & 2,88 \\
\hline & $\begin{array}{l}\text { Дефицит федерашьного } \\
\text { (центрашьного) бюджета, \% к ВВП }\end{array}$ & $\leq 3$ & 2,70 \\
\hline \multirow{4}{*}{$\begin{array}{l}\text { Отраслевые } \\
\text { индикаторы }\end{array}$} & Валовый сбор зерновых, млн т. & $\geq 60$ & 113,25 \\
\hline & Доля расходов на оборону, \% к ВВП & $\geq 3$ & 3,70 \\
\hline & $\begin{array}{l}\text { Доля инноващионной продукщии в } \\
\text { общем объеме промышленной } \\
\text { продукции, \% }\end{array}$ & $\geq 15$ & 6,00 \\
\hline & $\begin{array}{l}\text { Доля мапиностроения и } \\
\text { металлообработки в промышшенном } \\
\text { производстве, \% }\end{array}$ & $\geq 25$ & 12,00 \\
\hline \multirow{5}{*}{$\begin{array}{l}\text { Финансовые } \\
\text { индикаторы }\end{array}$} & $\begin{array}{l}\text { Валовое накопление основного } \\
\text { капитала, \% к ВВІІ }\end{array}$ & $\geq 16$ & 20,70 \\
\hline & $\begin{array}{l}\text { Объем государственных резервов, \% } \\
\text { к ВВП }\end{array}$ & $\geq 15$ & 28,27 \\
\hline & Уровень монетизации, \% к ВВП & $\leq 25$ & 43,22 \\
\hline & Внешний долг, \% к ВВП & $\leq 40$ & 31,26 \\
\hline & $\begin{array}{l}\text { Доля расходов бюджета на } \\
\text { обслуживание государственного } \\
\text { дола, \% от общего объёма расходов } \\
\text { бюджета }\end{array}$ & $\leq 10$ & 4,70 \\
\hline \multirow{4}{*}{$\begin{array}{l}\text { Социальные } \\
\text { индикаторы }\end{array}$} & $\begin{array}{l}\text { Доля затрат на науку и образование, } \\
\text { \% к ВВП }\end{array}$ & $\geq 1,5$ & 2,49 \\
\hline & $\begin{array}{l}\text { Доля лиц с денежным доходом ниже } \\
\text { прожиточного уровня во всей } \\
\text { численности населения, \% }\end{array}$ & $\leq 7$ & 12,60 \\
\hline & $\begin{array}{l}\text { Децијьный коэффициент } \\
\text { дифференциации доходов населения }\end{array}$ & $\leq 8$ & 6,33 \\
\hline & $\begin{array}{l}\text { Доля продовольствия, поступивпего } \\
\text { по импорту, в общем объеме } \\
\text { продовольственных ресурсов, \% }\end{array}$ & $\leq 20$ & 12,40 \\
\hline
\end{tabular}


Как можно увидеть, практически все индикаторы не выходят за рамки пороговых значений. Однако несколько показателей все же не соответствуют своим критическим значениям. Таким образом, среди названных показателей самыми высокими для Российской Федерации среди других перечисленных стран являются расходы на вооружение и размер государственных резервов. Остальные показатели на фоне других развитых государств являются относительно низкими, что указывает на недостаточное использование имеющегося потенциала. Показатель инфляции является самым большим среди развитых стран, средним является приток ПИИ. Высокий уровень вовлеченности рабочей силы объясняется сокращением её численности. Высок показатель накопления основного капитала, однако т. к. он выражен в процентах от ВВП, то его рост обусловлен снижением размера ВВП. Также следует отметить, что некоторые из отраслевых, финансовых и социальных индикаторов не соответствуют своим допустимым пределам.

Чтобы определить зависимость экономического роста страны от состояния её национальной экономической безопасности, разработана и эмпирически проверена экономико-математическая модель данной зависимости. В рамках этой модели была выявлена зависимость ВВП РФ от таких показателей, как: уровень безработицы, уровень инфляции; дефицит федерального (центрального) бюджета; доля расходов на оборону; доля инновационной продукции в общем объёме промышленной продукции; доля машиностроения и металлообработки в промышленном производстве; основной капитал; объём государственных резервов; уровень монетизации; внешний долг; доля расходов бюджета на обслуживание государственного долга; доля затрат на науку и образование; доля лиц с денежным доходом ниже прожиточного уровня; децильный коэффициент дифференциации доходов населения; доля продовольствия, поступившего по импорту, в общем объёме продовольственных ресурсов. Наиболее значимые для экономического роста показатели национальной экономической безопасности РФ в разрезе сравнения фактических значений данных показателей за 2018 г. с их допустимыми пороговыми значениями представлены в табл. 3.

Таким образом, экономико-математическое моделирование позволило выделить наиболее уязвимые показатели экономической безопасности, что может быть положено в основу оценки влияния глобальных угроз (коронакризис) на уровень экономической безопасности страны. На основе вышеизложенных данных можно сделать вывод, что наиболее слабыми сторонами в политике обеспечения экономической безопасности государства являются низкая доля машиностроения и металлообработки в промышленном производстве, уровень монетизации, а также высокая доля лиц с денежным доходом ниже 
прожиточного минимума. Из этого следует, что основные меры по укреплению национальной экономической безопасности должны быть направлены на улучшение данных показателей путем проведения структурных изменений некоторых аспектов внутренней и внешней политики.

Таблица 3

Наиболее значимые для экономического роста показатели национальной экономической безопасности

\begin{tabular}{|c|c|c|}
\hline Показатель & $\begin{array}{l}\text { Пороговые } \\
\text { значения }\end{array}$ & $\begin{array}{c}\text { Фактические } \\
\text { значения в } \\
2018 \text { г. } \\
\end{array}$ \\
\hline $\begin{array}{c}\text { Уровень безработицы, \% к экономически активному } \\
\text { населению }\end{array}$ & $\leq 8$ & 4,74 \\
\hline $\begin{array}{c}\text { Дефицит федерального (центрального) бюджета, \% к } \\
\text { ВВП }\end{array}$ & $\leq 3$ & 2,70 \\
\hline Доля расходов на оборону, \% к ВВП & $\geq 3$ & 3,70 \\
\hline $\begin{array}{c}\text { Доля мапиностроения и металлообработки в } \\
\text { промыпленном производстве, \% }\end{array}$ & $\geq 25$ & 12,00 \\
\hline Валовое накопление основного капитала, \% к ВВП & $\geq 16$ & 20,70 \\
\hline Уровень монетизации, \% к ВВП & $\leq 25$ & 43,22 \\
\hline $\begin{array}{c}\text { Доля расходов бюджета на обслуживание } \\
\text { государственного долга, \% от общего обтёма } \\
\text { расходов бюджета }\end{array}$ & $\leq 10$ & 4,70 \\
\hline Доля затрат на науку и образование, \% к ВВП & $\geq 1,5$ & 2,49 \\
\hline $\begin{array}{c}\text { Доля лиц с денежным доходом ниже грожиточного } \\
\text { уровня во всей численности населения, \% }\end{array}$ & $\leq 7$ & 12,60 \\
\hline $\begin{array}{c}\text { Доля продовольствия, поступившего по импорту, в } \\
\text { общем объёме продовольственных ресурсов, \% }\end{array}$ & $\leq 20$ & 12,40 \\
\hline
\end{tabular}

Раздел 4. Угрозы национальной экономической безопасности

Проведенное исследование в области обеспечения национальной экономической безопасности и её оценки позволило сделать вывод о том, что как внешние (пандемия, санкции), так и внутренние угрозы экономической безопасности имеют структурный комплексный характер. Иными словами, можно сказать, что основными предпосылками этих негативных условий стали неудовлетворительное экономическое развитие национальной экономики, недостаточное использование имеющегося экономического потенциала страны, постоянно растущее отставание национального научно-технического комплекса государства. 
Очевидно, что политика в области обеспечения экономической безопасности, проводимая правительством государства, является неэффективной на всех уровнях власти. Становится ясно, что основные противодействующие меры необходимо направить в первую очередь на минимизацию уже имеющихся негативных последствий, которые возникают вследствие определенных угроз национальной экономической безопасности. Данные угрозы можно разделить на внутренние и внешние.

К внутренним угрозам следует отнести: сохраняющиеся темпы старения населения, угроза повторения «демографической ямы», что в перспективе может привести к сокращению числа рабочей силы и увеличению нагрузки на оставшуюся рабочую силу; сохраняющаяся доля теневой экономики, расширение влияния преступной деятельности на отдельные сферы общественной жизни и, как результат, обострение социальных проблем; узкая направленность национального хозяйства, привязка к так называемой «сырьевой игле», отставание научнотехнологического комплекса, низкий уровень воспроизводства высокотехнологичных товаров, машиностроения, неэффективное использование имеющегося потенциала; неудовлетворительный уровень конкурентоспособности большинства отраслей национального воспроизводства, основными причинами которой являются: отставание научно-технологического комплекса и неэффективное использование имеющегося потенциала; низкое количество высокотехнологичной продукции и неудовлетворительное качество имеющейся; снижение национального научно-технического потенциала, низкое качество продуктов интеллектуального труда; недостаточное финансирование различных научных исследований и новейших разработок; растущий риск несчастных случаев и техногенных катастроф со значительными негативными последствиями для окружающей среды; сокращение природных ресурсов, необходимых для стабильного развития в сферах промышленности и энергетики; разрыв в социально-экономическом развитии регионов и Российской Федерации в целом; неэффективная система национального фондового рынка, учитывая зависимость национальной валюты от зарубежных платежных единиц и низкий уровень диверсификации структуры национального экспорта из-за достаточно высокой зависимости российской экономики от сырьевых рынков и др.

Перечисленные внутренние угрозы национальной экономической безопасности могут стать причиной серьезных негативных последствий, которые могут повлиять на всю национальную безопасность в целом.

Однако на основе проведенного в исследовании анализа факторов экономической безопасности можно сделать вывод, что даже при разработке политики по обеспечению национальной экономической безопасности, которая будет направлена на нейтрализацию всех 
перечисленных выше угроз, это не будет являться залогом высокого уровня экономической безопасности государства. Причиной этому является тот факт, что принятые меры будут направлены лишь на нейтрализацию внутренних угроз. Следует помнить о том, что обеспечение национальной экономической безопасности - это комплекс методов, направленных на нейтрализацию как внутренних, так и внешних негативных факторов.

К последним можно отнести такие факторы, как высокий уровень зависимости национальной экономики и составляющих от современных внешнеэкономических условий и влияние пандемии COVID-19. Факторы, определяющие угрозу внешнеэкономической сферы: низкая конкурентоспособность российских товаров на мировых и даже местных рынках, вследствие последнего происходит вытеснение продукции с государственного рынка и контроль над целевыми сегментами покупателей; определенные негативные действия некоторых иностранных государств или интеграционных объединений, которые направлены на ослабление российской экономики. Негативное влияние данных факторов в значительной мере отражается не только на экономической, но и социальной сфере государства; влияние внешнеэкономических санкций; неэффективная процедура экспортного контроля, а также валютного контроля экспортно-импортных операций; низкое развитие государственной транспортной инфраструктуры в экспортно-импортных операциях, которая замедляет торговые операции, также негативно влияет на внешнеторговые экономические отношения с иностранными партнерами.

Как внутренние, так и внешние угрозы несут в себе одинаковый уровень опасности, причем даже при нейтрализации внутренних угроз всегда будут возникать новые внутренние, и наоборот. К тому же внешние угрозы могут в некотором роде усиливать негативное действие внутренних отрицательных факторов, что доказывает структурный характер угроз национальной экономической безопасности.

При этом следует отметить, что Россия была лучше подготовлена к возникшему шоку, вызванному COVID-19, по сравнению с подавляющим числом стран мира, в том числе относящихся к экономически развитым. Низкий уровень внешнего государственного и частного долга, накопленные финансовые ресурсы Фонда национального благосостояния позволили сгладить негативное влияние текущей глобальной экономической ситуации, в том числе в части сохранения достаточного уровня устойчивости национальной валюты.

\section{Выводы}

Таким образом, можно сделать вывод, что в условиях современных глобальных вызовов экономическая безопасность Российской Федерации постоянно подвергается все новым возникающим угрозам. 
Разделить их можно как на внешние и внутренние, так и по сферам влияния на общественную жизнь, т. е. экономическую, социальную, технологическую, информационную и т. д. Влияние этих факторов оказывает негативное воздействие практически на все сферы жизни. К тому же важно отметить, что недостаточно разработать меры противодействия отдельным угрозам внешнеэкономической безопасности, т. к. воздействуют они структурно на всю общественную жизнь государства в целом, и мероприятия по нейтрализации этих угроз должны носить глубокий структурный и системный характер, направленный на каждый негативный фактор в отдельности и на все вместе в то же время.

Bce вышесказанное подтверждает утверждение, что обеспечение национальной экономической безопасности и нейтрализация всех возможных угроз в условиях пандемии является основополагающей задачей правительства любого государства. От успеха и эффективности противодействующих мероприятий зависит уровень экономического развития страны в целом и качество жизни его граждан.

Таким образом, можно сделать вывод, что экономическая безопасность государства может быть представлена как состояние защиты национальной экономики от внешних и внутренних угроз, которая обеспечивает поступательное развитие общества, его экономическую и социально-политическую стабильность, несмотря на наличие неблагоприятных внешних и внутренних факторов.

\section{Список использованных источников:}

1. Абалкин Л.И. Экономическая безопасность России: угрозы и их отражение. Вопросы экономики. 1994. № 12. С. 4-13.

2. Диагностика и мониторинг экономической безопасности страны : монография / В.В. Земсков и др. ; под науч. ред. В.В. Земскова. Москва : Прометей, 2020. 338 с.

3. Илларионов А.А. Критерии экономической безопасности. Вопросы экономики. 1998. № 10. С. 35-58.

4. Федеральная служба государственной статистики. URL: http://www.gks.ru/ (дата обращения: 10.05.2021).

5. Цейковец Н.В. Концептуальные подходы к пониманию и обеспечению национальной экономической безопасности: научные теории и государственные стратегии. Журнал Новой экономической ассоииащии. 2016. № 1(29). С. 129-157.

6. Экономическая безопасность России / под ред. В.К. Сенчагова. Москва : Дело, 2005. $896 \mathrm{c}$.

7. Cable V. What is International Economic Security? International Affairs (Royal Institute of International Affairs 1944). 1995. V. 71. № 2. P. 305-324.

8. Jiang Y. Economic Security: Redressing Imbalance. China Security. 2007. V. 3. № 2. P. 66-85.

9. Litvinenko A.N. Economic and national security: the problem of concepts correlating. Scientific and technical statements, S.-Petersburg State Polytechnic University, Economic sciences. 2013. № 3. P. 9-15.

10. Luciani G. The Economic Content of Security. Journal of Public Policy. 1988. V. 8. № 2. P. 151-173. 


\section{References:}

1. Abalkin L.I. (1994) Ekonomicheskaya bezopasnost' Rossii: ugrozy i ikh otrazheniye [Economic security of Russia: threats and their reflection]. Economic issues, no. 12, pp. 4-13.

2. Zemskov V.V., Dadalko V.A., Starovoytov V.G. (2020) Diagnostika i monitoring ekonomicheskoy bezopasnosti strany [Diagnostics and monitoring of the country's economic security]. Moscow: Prometey. (in Russian)

3. Illarionov A.A. (1998) Kriterii ekonomicheskoy bezopasnosti [Economic security criteria]. Economic issues, no. 10, pp. 35-38.

4. Federal'naya sluzhba gosudarstvennoy statistiki. Moscow, 2019. URL: http://www.gks.ru/ (accessed 23 June 2020).

5. Tseykovets N.V. (2016) Kontseptual'nyye podkhody k ponimaniyu i obespecheniyu natsional'noy ekonomicheskoy bezopasnosti: nauchnyye teorii i gosudarstvennyye strategii [Conceptual approaches to understanding and ensuring national economic security: scientific theories and state strategies]. Journal of the New Economic Association, no. 1(29), pp. 129-157.

6. Senchagova V.K. (ed.) (2005) Ekonomicheskaya bezopasnost' Rossii [Economic security of Russia]. Moscow: Delo. (in Russian)

7. Cable V. (1995) What is International Economic Security? International Affairs (Royal Institute of International Affairs 1944). vol. 71, no. 2, pp. 305-324.

8. Jiang Y. (2007) Economic Security: Redressing Imbalance. China Security. vol. 3, no. 2, pp. 66-85.

9. Litvinenko A.N. (2013) Economic and national security: the problem of concepts correlating. Scientific and technical statements, S.-Petersburg State Polytechnic University, Economic sciences. no. 3, pp. 9-15.

10. Luciani G. (1988) The Economic Content of Security. Journal of Public Policy, vol. 8, no. 2, pp. 151-173. 